M. Ueno · J. B. C. Carvalheira • R. C. Tambascia •

R. M. N. Bezerra • M. E. Amaral • E. M. Carneiro •

F. Folli · K. G. Franchini • M. J. A. Saad

\title{
Regulation of insulin signalling by hyperinsulinaemia: role of IRS-1/2 serine phosphorylation and the mTOR/p70 S6K pathway
}

Received: 18 May 2004 / Accepted: 11 November 2004 / Published online: 4 February 2005

C) Springer-Verlag 2005

\begin{abstract}
Aim/hypothesis: Several epidemiological studies have suggested an association between chronic hyperinsulinaemia and insulin resistance. However, the causality of this relationship remains uncertain. Methods: We performed chronic hyperinsulinaemic-euglycaemic clamps and delineated, by western blotting, an IR/IRSs/phosphatidylinositol 3-kinase(PI[3]K)/Akt pathway in insulin-responsive tissues of hyperinsulinaemic rats. IRS-1/2 serine phosphorylation, IR/protein tyrosine phosphatase 1B (PTP1B) association, and mammalian target of rapamycin (mTOR)/ p70 ribosomal S6 kinase (p70 S6K) activity were also evaluated in the liver, skeletal muscle and white adipose tissue of hyperinsulinaemic animals. Results: We found that chronic hyperinsulinaemic rats have insulin resistance and reduced levels of glycogen content in liver and muscle. In addition, we demonstrated an impairment of the insulin-induced IR/IRSs/PI(3)K/Akt pathway in liver and muscle of chronic hyperinsulinaemic rats that parallels increases in IRS1/2 serine phosphorylation, IR/PTP1B association and mTOR activity. Despite a higher association of IR/PTP1B, there was an increase in white adipose tissue of chronic hyperinsulinaemic rats in IRS-1/2 protein levels, tyrosine phosphorylation and IRSs/PI(3)K association, which led to an increase in basal Akt serine phosphorylation. No increases in IRS-1/2 serine phosphorylation and mTOR activity were observed in white
\end{abstract}

M. Ueno · J. B. C. Carvalheira - R. C. Tambascia ·

R. M. N. Bezerra - M. E. Amaral - E. M. Carneiro ·

K. G. Franchini - M. J. A. Saad

Department of Internal Medicine,

State University of Campinas (UNICAMP),

Campinas, São Paulo, Brazil

F. Folli

Department of Internal Medicine, HS Raffaele,

Milan, Italy

M. J. A. Saad $(\bowtie)$

Departamento de Clínica Médica, FCM-UNICAMP,

Cidade Universitária Zeferino Vaz,

Campinas, São Paulo, Brazil, 13081-970

e-mail: msaad@fcm.unicamp.br

Fax: +55-19-37888950 adipose tissue. Rapamycin reversed the insulin resistance and the changes induced by hyperinsulinaemia in the three tissues studied. Conclusions/interpretation: Our data provide evidence that chronic hyperinsulinaemia itself, imposed on normal rats, appears to have a dual effect, stimulating insulin signalling in white adipose tissue, whilst decreasing it in liver and muscle. The underlying mechanism of these differential effects may be related to the ability of hyperinsulinaemia to increase mTOR/p70 S6K pathway activity and IRS-1/2 serine phosphorylation in a tissuespecific fashion. In addition, we demonstrated that inhibition of the mTOR pathway with rapamycin can prevent insulin resistance caused by chronic hyperinsulinaemia in liver and muscle. These findings support the hypothesis that defective and tissue-selective insulin action contributes to the insulin resistance observed in hyperinsulinaemic states.

Keywords Insulin resistance $\cdot$ Hyperinsulinaemia $\cdot$ Signal transduction $\cdot$ IRS- $1 \cdot$ IRS- $2 \cdot$ mTOR

Abbreviations C: control - DTT: dithiothreitol - Grb2: growth factor receptor-binding protein $2 \cdot \mathrm{H}$ :

hyperinsulinaemic - IR: insulin receptor - $\mathrm{mTOR}$ :

mammalian target of rapamycin - p70 S6K: p70 ribosomal S6 kinase $\cdot$ PI(3)K: phosphatidylinositol 3-kinase - PKB: protein kinase B - PTP1B: protein tyrosine phosphatase 1B

\section{Introduction}

Insulin resistance precedes type 2 diabetes mellitus and is characterised by hyperinsulinaemia, which develops to counterbalance peripheral hormone resistance. This hyperinsulinaemia exacerbates the insulin resistance state $[1,2]$. Several epidemiological studies have suggested an association between chronic hyperinsulinaemia and reduced insulin sensitivity, and studies in different animal models and in humans suggest that chronic insulin infusion induces insulin resistance. However, the molecular mechanisms that contribute to insulin resistance in animals chronically infused with this hormone and the regulation 
of early steps in insulin action in classical insulin-sensitive tissues have not yet been investigated.

The insulin receptor (IR) is a protein with endogenous tyrosine kinase activity that, following activation by insulin, undergoes rapid autophosphorylation and subsequently phosphorylates intracellular protein substrates, including IRS-1 and IRS-2 [3]. IRS proteins act as messenger molecule-activated receptors to signalling with Src homology 2 domains, which are important steps in insulin action. After stimulation by insulin, IRS-1 and -2 associate with several proteins, including phosphatidylinositol 3-kinase (PI[3]K) $[4,5]$. Downstream to $\mathrm{PI}(3) \mathrm{K}$ the serine threonine kinase, Akt, is activated playing a pivotal role in the regulation of various biological processes, including apoptosis, proliferation, differentiation, and intermediary metabolism $[6,7]$.

Dephosphorylation of IR and IRS-1 by protein tyrosine phosphatase 1B (PTP1B) and serine phosphorylation of IRS proteins are believed to be major mechanisms of suppression of IR and IRS protein activities that contribute to insulin resistance [8-10]. Both regulation of IR dephosphorylation and serine phosphorylation of IRS proteins have been focused in the search for the molecular mechanism of insulin resistance. Thus, PTP1B knockout mice exhibit increased insulin sensitivity and are resistant to high-fat-diet-induced obesity [11], and several serine kinases, including the mammalian target of rapamycin (mTOR) [12], have been highlighted for their activities in insulin resistance by phosphorylating IRSs at serine residues [13-15]. However, the exact cellular mechanism of insulin resistance and the sequence of molecular alterations that occur in different tissues during hyperinsulinaemia remain unclear.

In this study, we performed a chronic hyperinsulinaemic-euglycaemic clamp procedure to delineate the IR/ IRSs/PI(3)K/Akt pathway in insulin-responsive tissues of hyperinsulinaemic rats. To gain further insight into the molecular mechanism of insulin resistance induced by hyperinsulinaemia, we also evaluated IRS- $1 / 2$ serine phosphorylation, IR/PTP1B association, and mTOR activity in liver, skeletal muscle and adipose tissue of hyperinsulinaemic animals.

\section{Materials and methods}

Materials The reagents and apparatus for SDS-PAGE and immunoblotting were from Bio-Rad (Richmond, CA, USA). Tris, phenylmethylsulphonylfluoride, dithiothreitol (DTT), Triton X-100, Tween 20 and glycerol were from Sigma Chemical (St. Louis, MO, USA). DMSO was from Calbiochem (La Jolla, CA, USA). Aprotinin was from Bayer (São Paulo, SP, Brazil). Ketamin was from ParkeDavis (São Paulo, SP, Brazil), diazepam and sodium thiopental were from Cristália (Itapira, SP, Brazil). Human recombinant insulin was from Biobrás (Montes Claros, MG, Brazil). Protein A-sepharose $6 \mathrm{MBq}$, nitrocellulose membrane (Hybond ECL, $0.45 \mu \mathrm{m}$ ) and $\left.{ }^{125}\right]$ I-Protein A were from Amersham (Buckinghamshire, UK). Tygon tube was from Norton Performance Plastics (CO, USA), poly- ethylene (PE 50) was from Clay Adams (Parsipany, USA), and the polyvinyl catheter was from Silverwater (BC, Australia). Antibiotic was from Fort Dodge (Campinas, SP, Brazil). Dacron was from BardDeBakey Elastic Knit Fabric C.R. Bard (USA). Dual-channel swivel infusion system was from Instech (Plymouth Meeting, USA). The syringe pump was from KD Scientific (model 200 series, USA). Monoclonal antiphosphotyrosine antibody (anti-PY), anti-IR, anti IRS-1, anti-IRS-2 and anti-PTP1B rabbit polyclonal antibodies were from Santa Cruz Biotechnology (Santa Cruz, CA, USA). Polyclonal anti-PI(3)K (p85), anti-IRS-2 and anti-mTOR (mTAB1/2) antibodies for immunoblotting were from Upstate Biotechnology (Lake Placid, NY, USA), and anti-phospho-Akt (Ser473) and anti-phospho-p70 S6K (Thr421/Ser424) antibodies were from New England Biolabs (Beverly, MA, USA). Phospho-serine antibodies were obtained from Chemicon International (Temecula, CA, USA). Rapamycin was from LC Laboratories (Woburn, MA, USA). Rat insulin, adiponectin, resistin, leptin and triglyceride kits were obtained from Linco Research (St. Charles, MO, USA).

Animals Adult male Wistar-Hannover rats (250-300 g), from the University's Central Animal Breeding Center, were used in all the experiments in accordance with the guidelines of the Brazilian College for Animal Experimentation (COBEA) and were approved by the ethics committee at the University of Campinas. Rats were housed individually in metabolic cages under conditions of constant temperature $\left(20-22^{\circ} \mathrm{C}\right)$ and subjected to a standard light-dark cycle (06.00-18.00/18.00-06.00 hours) and provided with standard rodent chow and water ad libitum. Different groups of rats were used for tissue sampling and the biochemical assays.

Surgical and experimental procedure Chronic hyperinsulinaemia was created using a modification of the euglycaemic insulin clamp technique [16]. Three days before the start of the chronic insulin infusion, rats were anaesthetised with an intraperitoneal injection of a mix of ketamin (10 mg Ketalar) and diazepam $(0.07 \mathrm{mg})(0.2$ $\mathrm{ml} / 100 \mathrm{~g}$ body weight), and catheters were inserted as follows: (1) a polyethylene catheter (PE 50) into the right femoral vein; and (2) a catheter made of Tygon and polyvinyl into the right femoral artery. The femoral vein catheter was used for infusion of fluids, and the femoral artery catheter was used for blood sampling. Antibiotic was administered intramuscularly, and both catheters were routed subcutaneously and exteriorised at the back of the neck through a subcutaneously sutured Dacron-covered button.

The rats were permanently connected to a dual-channel swivel insulin/glucose infusion system mounted above the metabolic cage and were protected by a stainless steel spring that also served as a tethering device. All solutions were infused with a syringe pump. After surgery, the animals were allowed to recover for 3 days. During these days, the rats were adapted to the experimental procedure. 
After the adaptation period and round-the-clock control measurements, insulin was infused for 5 days at a constant rate of $1.25 \mathrm{mU} \mathrm{kg}^{-1} \mathrm{~min}^{-1}$, with a $25 \%$ glucose infusion that was adjusted periodically to maintain euglycaemia. Plasma glucose was measured twice in the morning and twice in the afternoon. Plasma glucose levels were kept between 5 and $6.1 \mathrm{mmol} / \mathrm{l}$. The rapamycin group was injected subcutaneously with this drug (solubilised in DMSO and diluted to a final concentration of $4 \mathrm{mg} / \mathrm{kg}$ ) once daily, for 5 days. Injections were initiated 1 day prior to the beginning of each experiment. The control group received an equal daily volume of saline $(0.9 \% \mathrm{NaCl})$ to mimic the water/electrolyte load in the hyperinsulinaemic group.

Euglycaemic-hyperinsulinaemic clamp At 14.00 hours on day 5 , after a 6-h fast, a prime continuous $\left(3.0 \mathrm{mU} \cdot \mathrm{kg}^{-1} \cdot \mathrm{min}^{-1}\right)$ infusion of regular insulin was administrated for $2 \mathrm{~h}$ from time 0 , to raise plasma insulin and maintain it in a steady state plateau (90-120 min) in hyperinsulinaemic and control rats. A variable glucose infusion $(10 \%)$ was started 5 min after the beginning of the experiment and was corrected, if necessary, to maintain euglycaemia between 5 and $6.1 \mathrm{mmol} / 1$ [17]. Blood samples for determination of plasma glucose were obtained at 5-min intervals throughout the study.

Tissue extracts After a 6-h fast, control and hyperinsulinaemic rats were anaesthetised intraperitoneally with sodium thiopental $(80 \mathrm{mg} / \mathrm{kg}$ body weight $)$ and used as soon as they were fully anaesthetised (loss of pedal and corneal reflexes). The abdominal cavity was opened, the portal vein exposed, and $60 \mu \mathrm{g}$ insulin were injected. After $30 \mathrm{~s}$, the liver was removed, minced coarsely and homogenised immediately in 10 volumes of solubilisation buffer $(10 \mathrm{ml} / 1$ Triton-X $100,100 \mathrm{mmol} / 1 \mathrm{Tris} \mathrm{pH} 7.4,10 \mathrm{mmol} / 1$ sodium pyrophosphate, $100 \mathrm{mmol} / 1$ sodium fluoride, $10 \mathrm{mmol} / \mathrm{l}$ EDTA, 10 $\mathrm{mmol} / \mathrm{l}$ sodium vanadate, $2 \mathrm{mmol}$ phenylmethylsulfonyl fluoride and $0.1 \mathrm{mg} / \mathrm{ml}$ aprotinin at $4{ }^{\circ} \mathrm{C}$, using a polytron PTA 20S generator (model PT 10/35; Brinkmann Instruments, Westbury, NY, USA) operated at maximum speed for $20 \mathrm{~s}$. Approximately $90 \mathrm{~s}$ after the insulin injection, hindlimb muscle and adipose tissue samples were excised and homogenised as described above. The tissue extracts were centrifuged at $12,000 \mathrm{~g}$ at $4^{\circ} \mathrm{C}$ for $20 \mathrm{~min}$, and the supernatants used as sample.

Protein analysis by immunoblotting For immunoprecipitation, the supernatants were incubated overnight at $4^{\circ} \mathrm{C}$ with antibodies against IR, IRS-1 or IRS-2, followed by the addition of protein A-sepharose $6 \mathrm{MBq}$. The samples (immunoprecipitated proteins and total extracts) were treated with Laemmli buffer [18] containing $100 \mathrm{mmol} / \mathrm{l} \mathrm{DTT}$, heated in a boiling water bath for $4 \mathrm{~min}$ and subjected to $8 \%$ SDS-PAGE in a Bio-Rad minigel apparatus (Mini-Protean; Bio-Rad). The prestained molecular mass standards used were myosin $\left(205 M_{\mathrm{r}}\right)$, galactosidase $\left(116 M_{\mathrm{r}}\right)$, BSA $\left(80 M_{\mathrm{r}}\right)$ and ovalbumin $\left(49.5 M_{\mathrm{r}}\right)$. Electrotransfer of proteins from the gel to the nitrocellulose membranes was performed for
90 min at $120 \mathrm{~V}$ (constant) in a Bio-Rad miniature transfer apparatus (Mini-Protean) as described by [19], but with $0.02 \%$ SDS and $\beta$-mercaptoethanol added to the transfer buffer to enhance the elution of high-molecular-mass proteins. The non-specific protein binding to the nitrocellulose was reduced by pre-incubating the filter for $2 \mathrm{~h}$ at $22^{\circ} \mathrm{C}$ in blocking buffer $(5 \%$ non-fat dried milk, $10 \mathrm{mmol} / \mathrm{l}$ Tris, $150 \mathrm{mmol} / \mathrm{l} \mathrm{NaCl}$, and $0.02 \%$ Tween 20 ). The nitrocellulose blots were incubated for $4 \mathrm{~h}$ at $22^{\circ} \mathrm{C}$ with antibodies against phosphotyrosine, IR, IRS- 1 , IRS-2, the $\mathrm{p} 85$ subunit of PI(3)K, phospho-Akt, phospho-serine or PTP1B diluted in blocking buffer ( $3 \%$ non-fat dried milk, $10 \mathrm{mmol} / 1$ Tris, $150 \mathrm{mmol} / 1 \mathrm{NaCl}$, and $0.02 \%$ Tween 20 ), followed by washing for $30 \mathrm{~min}$ in blocking buffer without milk. The blots were incubated with $0.074 \mathrm{MBq}$ of $\left[{ }^{125} \mathrm{I}\right]$ protein A $(1.11 \mathrm{MBq} / \mu \mathrm{g})$ in $10 \mathrm{ml}$ of blocking buffer $(1 \%$ non-fat dried milk) for $1 \mathrm{~h}$ at $22^{\circ} \mathrm{C}$ and washed again as described above. $\left[{ }^{125} \mathrm{I}\right]$ Protein $\mathrm{A}$ bound to the antibodies was detected by autoradiography using preflashed Kodak XAR film (Eastman Kodak, Rochester, NY, USA) with a Cronex Lightning Plus intensifying screen (DuPont, Wilmington, DE, USA) at $-80^{\circ} \mathrm{C}$ for 12 to $48 \mathrm{~h}$. Images of the developed autoradiographs were scanned (Hewlett Packard Scanjet 5P) and band intensities were quantitated by optical densitometry (Scion Image Corporation) of the developed autoradiographs that were used at exposures in the linear range.

For IR, IRS-1, IRS-2, phospho-Akt, mTOR and phosphop70 S6K quantitation in either tissue, total extract samples (250 $\mu \mathrm{g}$ protein) were subjected to SDS-PAGE with no previous immunoprecipitation. After electrophoretic separation, proteins were transferred to nitrocellulose membranes and then blotted with specific antibody. Quantitative analysis was performed as described above.

Other assays Protein quantification was performed using the Bradford method [20]. Glucose levels were measured by the glucose oxidase method [21]. Plasma insulin, adiponectin, resistin, and leptin were determined at the end of the fifth day of insulin or saline infusion after a 6-h fast, by radioimmunoassay using rat standard [22]. Hepatic and muscular glycogen content was determined according to [23]. Plasma total cholesterol and triglycerides levels were measured enzymatically (Boehringer Mannheim, Indianapolis, IN, USA) on an Hitachi 704 autoanalyser.

Statistical analysis Where appropriate, the results were expressed as the means \pm SEM accompanied by the indicated number of rats used in experiments. Comparisons among groups were made using parametric two-way ANOVA. Further comparisons were made using the Newman-Keuls test. A $p$ value of less than 0.05 was considered statistically significant.

\section{Results}

Animal characteristics The clinical and laboratory data of control and hyperinsulinaemic rats are summarised in 
Table 1. There were no differences in body weight and food intake between control and hyperinsulinaemic rats. Compared with control rats, the epididymal fat pad weight and the epididymal cell volume were about 1.4-fold higher in hyperinsulinaemic rats. Total plasma triglycerides and cholesterol levels were similar between controls and hyperinsulinaemic rats. The whole-body insulin-mediated glucose disposal during the euglycaemic insulin clamp was significantly lower in rats treated with insulin for 5 days than in controls. Chronic euglycaemic hyperinsulinaemia, imposed for 5 days on normal rats, resulted in a decrease in the glycogen content in liver and muscle, when compared to the controls. As expected, the fasting plasma insulin levels were significantly higher in chronic insulintreated rats than in the control rats. There were no differences in leptin, adiponectin and resistin levels between control and hyperinsulinaemic rats.

Effect of chronic euglycaemic hyperinsulinaemia on insulin signal transduction in the liver of rats Insulin-induced IR tyrosine phosphorylation was reduced in the liver of hyperinsulinaemic animals (Control [C]: $100 \pm 4$ vs Hyperinsulinaemic [H]: $68 \pm 4 \%, p<0.05 ; n=8$, Fig. 1a, left panel). There was no difference in IR protein expression in the muscle of control and hyperinsulinaemic rats (Fig. 1a, middle panel). When data were expressed as a function of the amount of IR there was no change in the stoichiometry of IR phosphorylation in the liver of hyperinsulinaemic rats (data not shown). To determine whether the decreases in IR tyrosine phosphorylation in the hyperinsulinaemic rats were associated with an increase in IR/PTP1B association, we carried out immunoprecipitation with anti-IR antibody and then blotted with anti-PTP1B antibody. The basal levels of IR/PTP1B association were 2.5-fold higher

Table 1 Characteristics of the animals

\begin{tabular}{|c|c|c|c|}
\hline Parameter & $\begin{array}{l}\text { Control } \\
(n=8)\end{array}$ & $\begin{array}{l}\text { Hyperinsulinaemic } \\
(n=8)\end{array}$ & $\begin{array}{l}p \\
\text { value }\end{array}$ \\
\hline Body weight (g) & $274 \pm 13$ & $265 \pm 11$ & 0.605 \\
\hline Food intake (g/day) & $20 \pm 3$ & $17 \pm 2$ & 0.419 \\
\hline $\begin{array}{l}\text { Epididymal fat } \\
\operatorname{pad}(\mathrm{g})\end{array}$ & $1.04 \pm 0.09$ & $1.38 \pm 0.08$ & 0.013 \\
\hline $\begin{array}{l}\text { Epididymal fat cell volume } \\
\left(\mu \mathrm{m}^{2}\right)\end{array}$ & $1437 \pm 92$ & $1874 \pm 78$ & 0.003 \\
\hline Triglycerides (mg/dl) & $73 \pm 8$ & $64 \pm 9$ & 0.467 \\
\hline Cholesterol (mg/dl) & $53 \pm 4$ & $49 \pm 7$ & 0.627 \\
\hline Glucose disposal ( $\mathrm{mg} / \mathrm{kg} \mathrm{min})$ & $19 \pm 2$ & $11 \pm 1$ & 0.003 \\
\hline $\begin{array}{l}\text { Hepatic glycogen levels } \\
\text { (mg/100 mg of tissue) }\end{array}$ & $3.0 \pm 0.3$ & $2.25 \pm 0.15$ & 0.04 \\
\hline $\begin{array}{l}\text { Muscle glycogen levels } \\
\text { (mg/100 mg of tissue) }\end{array}$ & $0.52 \pm 0.07$ & $0.33 \pm 0.02$ & 0.021 \\
\hline $\begin{array}{l}\text { Serum insulin levels } \\
(\mathrm{ng} / \mathrm{ml})\end{array}$ & $1.47 \pm 0.6$ & $3.6 \pm 0.3$ & 0.007 \\
\hline Leptin (pg/ml) & $2011 \pm 198$ & $2060 \pm 293$ & 0.892 \\
\hline Adiponectin $(\mu \mathrm{g} / \mathrm{ml})$ & $1.42 \pm 0.1$ & $1.2 \pm 0.3$ & 0.498 \\
\hline Resistin (ng/ml) & $3.46 \pm 0.2$ & $3.06 \pm 0.5$ & 0.470 \\
\hline
\end{tabular}

in hyperinsulinaemic than in control rats $(\mathrm{C}: 100 \pm 2 \mathrm{vs} \mathrm{H}$ : $253 \pm 11 \%, p<0.05 ; n=8$, Fig. 1a, right panel).

There were no differences in insulin-stimulated IRS-1 tyrosine phosphorylation in hyperinsulinaemic rats, when compared with controls (Fig. 1b, upper panel). Insulininduced IRS-2 tyrosine phosphorylation was decreased in the liver of hyperinsulinaemic animals by $48 \%$ (C: $100 \pm 5$ vs H: $52 \pm 5 \%, p<0.05 ; n=8$, Fig. 1c, upper panel). The same membranes used to detect tyrosine phosphorylation of IRS-1 and IRS-2 were reblotted with antibodies against the p85 subunit of PI(3)K. PI(3)K association with IRS-1 and IRS-2 paralleled the changes in phosphorylation of these proteins, with no difference in the IRS-1/PI (3)-K association in the liver of control and hyperinsulinaemic rats (Fig. 1b, lower panel), and the IRS-2/PI (3)-K association in hyperinsulinaemic animals was significantly lower than control animals (C: $100 \pm 7$ vs $H$ : $67 \pm 5 \%, p<0.05$; $n=8$, Fig. 1c, lower panel). The basal levels of IRS- 1 and IRS-2 serine phosphorylation were compared in IRS-1 and IRS-2 immunoprecipitates from the liver of control and hyperinsulinaemic rats. The basal levels of IRS- 1 and IRS-2 serine phosphorylation were higher in hyperinsulinaemic rats than in the control ones (C: $100 \pm 9$ vs $\mathrm{H}$ : $157 \pm 8 \%$; C: $100 \pm 5$ vs H: $152 \pm 8 \%$ respectively, $p<0.05$; $n=8$; Fig. 1d, e, upper panels). Protein expression of IRS-1 and IRS-2 in the liver from control and hyperinsulinaemic rats were quantitated by immunoprecipitation and immunoblotting with anti-IRS-1 or anti-IRS-2 antibodies and there were no differences in levels of these proteins (Fig. 1d, e, lower panels). With respect to phosphorylation, when data were corrected for the change in the number of IRS-1 molecules, no change in the stoichiometry of IRS-1 tyrosine phosphorylation was observed in hyperinsulinaemic rats. However a greater than twofold increase in IRS-1 serine phosphorylation was observed in these rats (Fig. 1f). The stoichiometry of IRS-2 tyrosine phosphorylation did not change, although there was a 1.5fold increase in the stoichiometry of IRS-2 serine phosphorylation (Fig. 1g).

We analysed insulin-induced Akt serine phosphorylation in whole tissue extract using an anti-phospho Akt antibody. After stimulation with insulin, a band was observed indicating that Akt is phosphorylated in control and hyperinsulinaemic rats. Based on immunoreactivity, the insulin-induced phosphorylation level of Akt was lower in the liver of hyperinsulinaemic rats than in control rats $(\mathrm{C}$ : $100 \pm 3$ vs H: $62 \pm 4 \%, p<0.05$; $n=8$, Fig. $2 \mathrm{a}$, upper panel). There was no difference in Akt protein levels between groups (Fig. 2a, lower panel).

Basal mTOR protein expression (C: $100 \pm 7$ vs H: $144 \pm$ $18 \%, p<0.05$; $n=8$; Fig. $2 \mathrm{~b}$ ) and basal serine phosphorylation of p70 S6K (C: $100 \pm 9$ vs H: $240 \pm 21 \%, p<0.05$; $n=8$; Fig. 2c) were higher in hyperinsulinaemic animals.

Effect of chronic euglycaemic hyperinsulinaemia on insulin signal transduction in skeletal muscle of rats Insulininduced IR tyrosine phosphorylation was reduced in the muscle of hyperinsulinaemic animals $(\mathrm{C}: 100 \pm 5$ vs $\mathrm{H}: 61 \pm$ $4 \%, p<0.05 ; n=8$, Fig. $3 \mathrm{a}$, left panel). There was no dif- 
Fig. 1 Insulin signalling in the liver of controls $(C)$ and hyperinsulinaemic $(H)$ rats. Liver extracts from rats injected with saline $(-)$ or insulin $(+)$ were prepared (see Materials and methods). Tissue extracts

(a) were immunoprecipitated (IP) with anti-IR antibody and immunoblotted $(I B)$ with antiPY antibody (left panel), anti-IR (middle panel), and anti-PTP1B (right panel). Tissue extracts (b-e) were also immunoprecipitated with anti-IRS-1 antibodies and immunoblotted with anti-

PY, anti-PI(3)K antibodies, antipSer, anti-IRS-1, and anti-IRS-2 (see panel labelling). f, g Phosphate stoichiometry. The results of scanning densitometry $(n=8)$ are expressed as arbitrary units. Columns and bars represent the mean \pm SEM. $* p<0.05$, control vs hyperinsulinaemic a

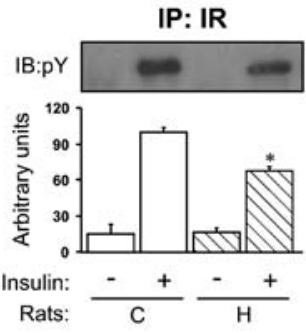

b
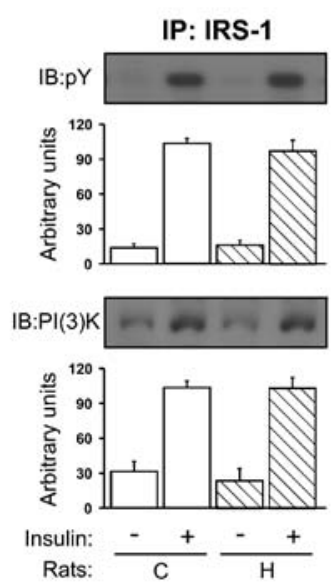

C

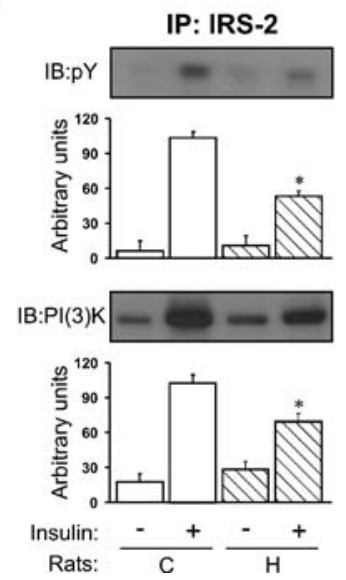

IP: IR

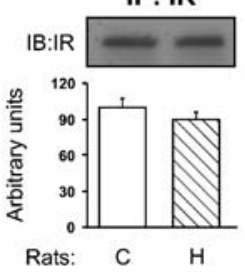

d

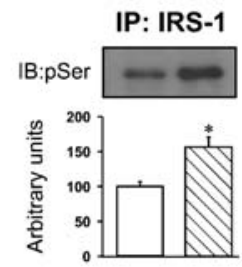

IB:IRS-1 - -

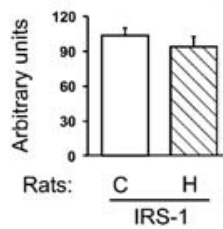

e

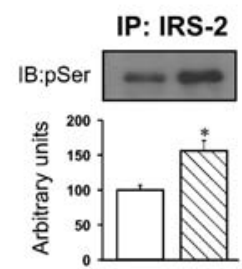

IB:IRS-2 $=$

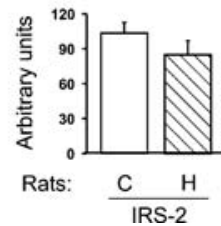

IRS-1

Phosphate (Tyr)

protein

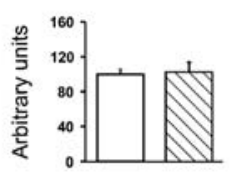

Phosphate (Ser) protein

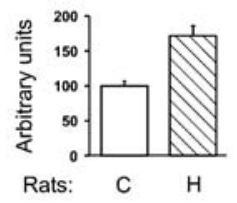

g

IRS-2

Phosphate (Tyr) protein

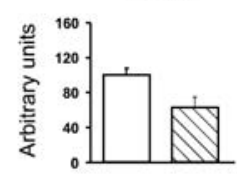

Phosphate (Ser) protein

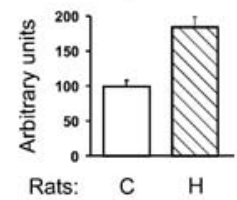

a

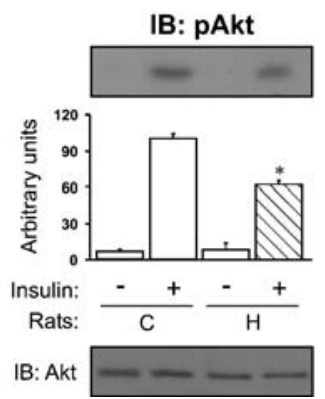

Fig. 2 Insulin signalling in the liver of control $(C)$ and hyperinsulinaemic $(H)$ rats. Liver extracts from rats injected with saline $(-)$ or insulin $(+)$ were prepared (see Materials and methods). Whole-tissue extracts were immunoblotted $(I B)$ with anti-phospho Akt (a), anti-
mTOR (b), or anti-phospho-p70 S6K antibodies (c). The results of scanning densitometry $(n=8)$ are expressed as arbitrary units. Columns and bars represent the mean \pm SEM. ${ }^{*} p<0.05$, control vs hyperinsulinaemic 
ference in IR protein expression in the muscle of control and hyperinsulinaemic rats (Fig. 3a, middle panel). When data were expressed as a function of the amount of IR, there were no changes in the stoichiometry of IR phosphorylation in the muscle of hyperinsulinaemic rats (data not shown). To determine whether the decreases in IR tyrosine phosphorylation in the hyperinsulinaemic rats were associated with an increase in IR/PTP1B association, we carried out immunoprecipitation with anti-IR antibody and then blotted with anti-PTP1B antibody. The basal levels of IR/PTP1B association were 2.3-fold higher in hyperinsulinaemic than in control rats (C: $100 \pm 3$ vs H: $232 \pm 14 \%, p<0.05 ; n=8$; Fig. 3a, right panel).

Insulin-induced IRS-1 tyrosine phosphorylation was decreased in the muscle of hyperinsulinaemic animals $(\mathrm{C}$ :
$100 \pm 3$ vs H: $73 \pm 8 \%, p<0.05$; $n=8$; Fig. 3 b, upper panel). There were no differences in insulin-stimulated IRS-2 tyrosine phosphorylation in hyperinsulinaemic animals when compared with controls (Fig. 3c, upper panel). The same membranes used to detect tyrosine phosphorylation of IRS-1 and IRS-2 were reblotted with antibodies against the p85 subunit of $\mathrm{PI}(3) \mathrm{K}$. PI(3)K association with IRS-1 and IRS-2 paralleled the changes in phosphorylation of these proteins, IRS-1/PI(3)K association in hyperinsulinaemic animals was significantly lower than in controls $(\mathrm{C}$ : $100 \pm 4$ vs H: $59 \pm 6 \%, p<0.05$; $n=8$; Fig. 3 b, lower panel). No difference in IRS-2/PI(3)K association in the muscle of control and hyperinsulinaemic rats was observed (Fig. 3c, lower panel). The basal levels of IRS-1 and IRS-2 serine phosphorylation were compared in IRS-1 and IRS-2 im-
Fig. 3 Insulin signalling in the muscle of controls $(C)$ and hyperinsulinaemic $(H)$ rats. Muscle extracts from rats injected with saline $(-)$ or insulin $(+)$ were prepared (see Materials and methods). Tissue extracts (a) were immunoprecipitated (IP) with anti-IR antibody and immunoblotted $(I B)$ with antiPY antibody (left panel), anti-IR (middle panel), and anti-PTP1B (right panel). Tissue extracts (b-e) were also immunoprecipitated with anti-IRS-1 and anti-IRS-2 antibodies and immunoblotted with anti-PY, anti-PI (3)K antibodies, anti-pSer, antiIRS-1 and anti-IRS-2 (see panel labelling). Phosphate stoichiometry is shown $(\mathbf{f}, \mathbf{g})$. The results of scanning densitometry $(n=8)$ are expressed as arbitrary units. Columns and bars represent the mean \pm SEM. ${ }^{*} p<0.05$, control vs hyperinsulinaemic
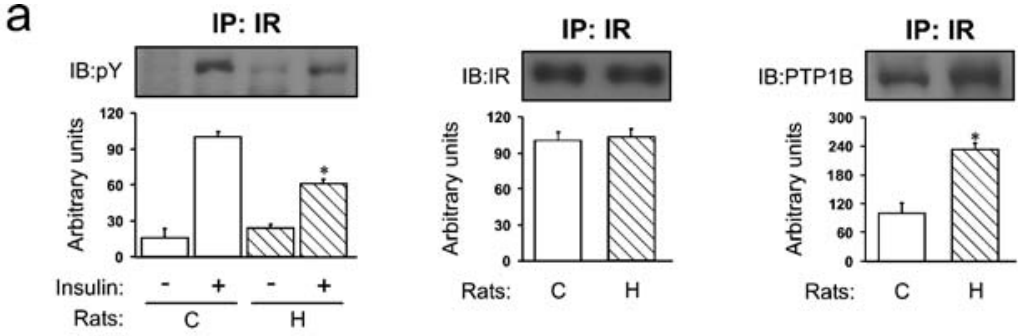

b
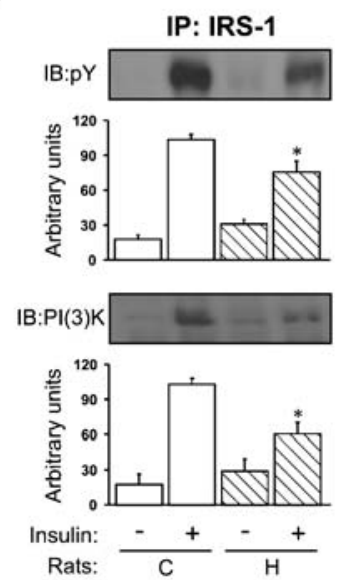

C

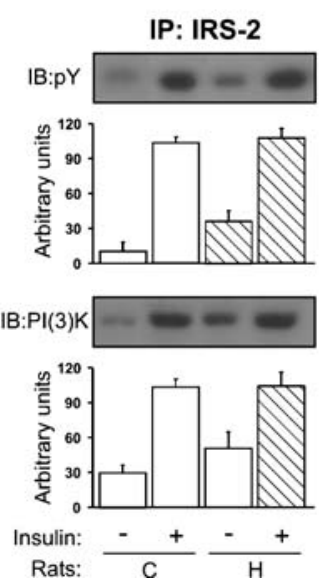

d
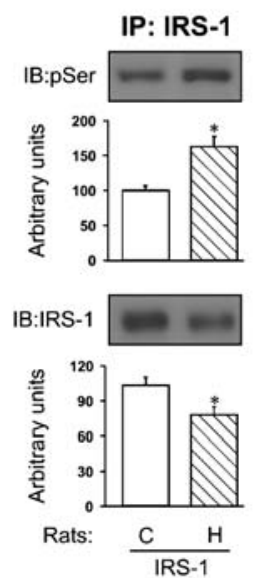

e
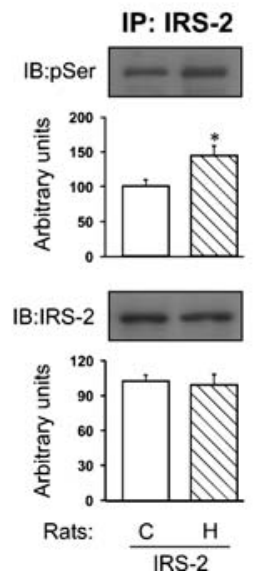

f

IRS-1

Phosphate (Tyr) protein

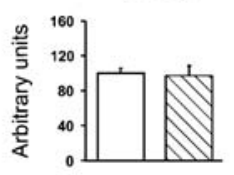

Phosphate (Ser) protein

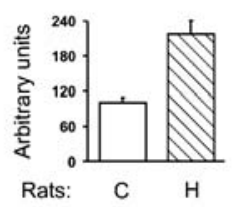

g

IRS-2

Phosphate (Tyr)/ protein

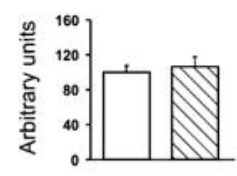

Phosphate (Ser) protein

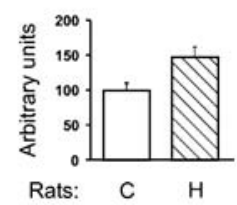


munoprecipitates from the muscle of control and hyperinsulinaemic rats. The basal levels of IRS-1 and IRS-2 serine phosphorylation were higher in hyperinsulinaemic rats than in the control ones (C: $100 \pm 4$ vs H: $163 \pm 8 \%$; C: $100 \pm 4$ vs H: $144 \pm 5 \%$ respectively, $p<0.05 ; n=8$; Fig. 3 d, e, upper panels). Protein expression of IRS-1 and IRS-2 from control and hyperinsulinaemic rats were quantitated by immunoprecipitation and immunoblotting with anti-IRS-1 or anti-IRS-2 antibodies and a reduction in the IRS-1 protein level in the muscle of hyperinsulinaemic animals was observed (C: $100 \pm 5$ vs H: $75 \pm 4 \%, p<0.05 ; n=8$; Fig. 3d, lower panel), without any difference in IRS-2 protein expression (Fig. 3e, lower panel). When data were corrected for the change in the number of IRS-1 molecules, the results were divergent, with a modest decrease in the apparent stoichiometry of IRS-1 tyrosine phosphorylation. In contrast, a more than twofold increase in IRS-1 serine phosphorylation was observed in the hyperinsulinaemic rats. Thus, the hyperinsulinaemia-induced decrease in the phosphorylation of IRS-1 protein might be of limited biological significance, since the number of IRS-1 molecules was decreased and overall phosphorylation slightly reduced when compared to control rats (Fig. 3f). The stoichiometry of IRS-2 tyrosine and serine phosphorylation did not change (Fig. 3g).

We analysed insulin-induced Akt serine phosphorylation in whole tissue extract using an anti-phospho Akt antibody. After stimulation with insulin, a band was observed indicating that Akt is phosphorylated in control and hyperinsulinaemic rats. Based on immunoreactivity, the insulin-induced phosphorylation level of Akt was lower in the muscle of hyperinsulinaemic rats than in that of controls (C: $100 \pm 3$ vs H: $72 \pm 7 \%, p<0.05$; $n=8$; Fig. 4a). There was no difference in Akt protein levels between groups (Fig. 4a, lower panel).

Basal mTOR protein expression (C: $100 \pm 8$ vs H: $223 \pm$ $21 \%, p<0.05$; $n=8$; Fig. 4b) and basal serine phosphorylation of p70 S6K (C: $100 \pm 6$ vs H: $281 \pm 19 \%, p<0.05 ; n=8$, Fig. $4 c)$ were higher in hyperinsulinaemic animals.

Effect of chronic euglycaemic hyperinsulinaemia on insulin signal transduction in white adipose tissue of rats In this tissue, there were no differences in insulin-induced IR tyrosine phosphorylation of hyperinsulinaemic animals when compared with their controls (Fig. 5a, left panel), and no changes in IR protein expression of control and hyperinsulinaemic rats (Fig. 5a, middle panel). When data were expressed as a function of the amount of IR, there were no changes in the stoichiometry of IR tyrosine phosphorylation in the white adipose tissue of hyperinsulinaemic rats (data not shown). To determine IR/PTP1B association, we carried out immunoprecipitation with antiIR antibody and then blotted with anti-PTP1B antibody. The basal levels of IR/PTP1B association were higher in hyperinsulinaemic than in control rats (C: $100 \pm 2$ vs $\mathrm{H}$ : $251 \pm 11 \%, p<0.05 ; n=8$; Fig. 5a, right panel).

Basal and insulin-induced IRS-1 tyrosine phosphorylations were higher in hyperinsulinaemic animals (basal: $\mathrm{C}$ : $30 \pm 6$ vs H: $115 \pm 32 \%, p<0.05$; insulin-induced: C: $100 \pm 8$ vs $\mathrm{H}: 352 \pm 21 \%, p<0.05 ; n=8$; Fig. $5 \mathrm{~b}$, upper panel). Similarly, there were increases in basal and insulin-induced IRS-2 tyrosine phosphorylation in hyperinsulinaemic animals (basal: C: $35 \pm 15$ vs H: $99 \pm 18 \%, p<0.05$; insulin-induced: C: $100 \pm 19$ vs H: $228 \pm 28 \%, p<0.05$; $n=8$; Fig. 5 c, upper panel). The same membranes used to detect tyrosine phosphorylation of IRS-1 and IRS-2 were reblotted with antibodies against the p85 subunit of PI(3)K. PI(3)K association with IRS-1 and IRS-2 paralleled the changes in phosphorylation of these proteins, with an increase in IRS$1 / \mathrm{PI}(3) \mathrm{K}$ association, before and after insulin stimulation, in the adipose tissue of hyperinsulinaemic rats as compared with control rats (basal: C: $11 \pm 5$ vs $\mathrm{H}: 121 \pm 27 \%, p<0.05$; insulin-induced: C: $100 \pm 8$ vs H: $180 \pm 17 \%, p<0.05 ; n=8$; Fig. 5b, lower panel). The basal and insulin-induced IRS-2/ $\mathrm{PI}(3) \mathrm{K}$ association was significantly higher in hyperinsulinaemic animals than controls (basal: C: $18 \pm 11$ vs $\mathrm{H}: 103 \pm$ $9 \%, p<0.05$; insulin-induced: C: $100 \pm 5$ vs $\mathrm{H}: 163 \pm 10 \%$, $p<0.05 ; n=8$; Fig. 5 c, lower panel). The basal levels of IRS-1 and IRS-2 serine phosphorylation were compared in IRS-1 and IRS-2 immunoprecipitates from the adipose tissue of control and hyperinsulinaemic rats. The basal levels of IRS1 and IRS-2 serine phosphorylation in the white adipose tissue from control and hyperinsulinaemic rats were quantitated by immunoprecipitation and immunoblotting with anti-IRS-1 or anti-IRS-2 antibodies, and there were no differences (Fig. 5d, e, upper panels). Protein expression of a

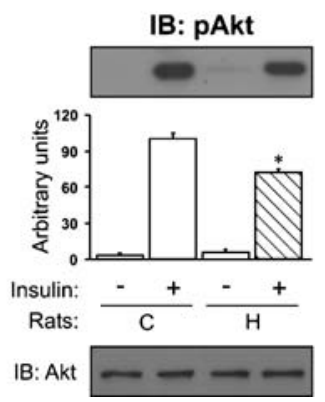

b

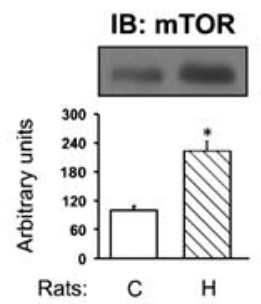

C

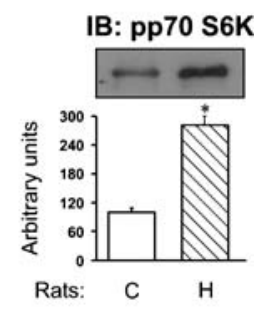

Fig. 4 Insulin signalling in the muscle of controls $(C)$ and hyperinsulinaemic $(H)$ rats. Muscle extracts from rats injected with saline $(-)$ or insulin $(+)$ were prepared (see Materials and methods). Wholetissue extracts were immunoblotted $(I B)$ with anti-phospho Akt (a),
anti-mTOR (b), or anti-phospho-p70 S6K antibodies (c). The results of scanning densitometry $(n=8)$ are expressed as arbitrary units. Columns and bars represent the mean \pm SEM. ${ }^{*} p<0.05$, control vs hyperinsulinaemic 
Fig. 5 Insulin signalling in the white adipose tissue of controls $(C)$ and hyperinsulinaemic $(H)$ rats. White adipose tissue extracts from rats injected with saline $(-)$ or insulin $(+)$ were prepared (see Materials and methods). Tissue extracts (a) were immunoprecipitated (IP) with anti-IR antibody and immunoblotted $(I B)$ with anti-PY antibody (left panel), anti-IR (middle panel) and anti-PTP1B (right panel). Tissue extracts (b-e) were also immunoprecipitated with anti-IRS-1 and anti-IRS-2 antibodies and immunoblotted with anti-PY, anti-PI (3)K antibodies, anti-pSer, antiIRS-1 and anti-IRS-2 (see panel labelling). Phosphate stoichiometry is also shown (f, g). The results of scanning densitometry $(n=8)$ are expressed as arbitrary units. Columns and bars represent the mean \pm SEM. ${ }^{*} p<0.05$, control vs hyperinsulinaemic a

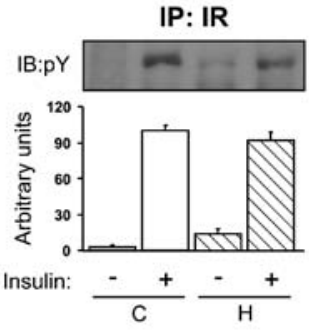

b
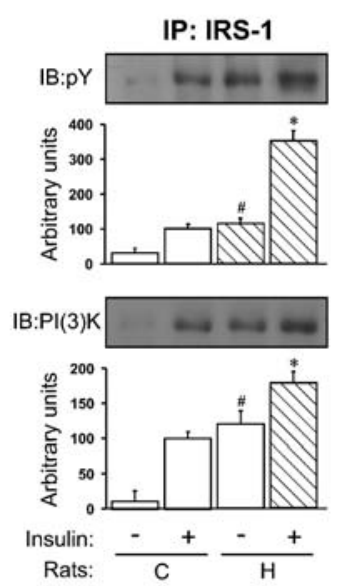

C
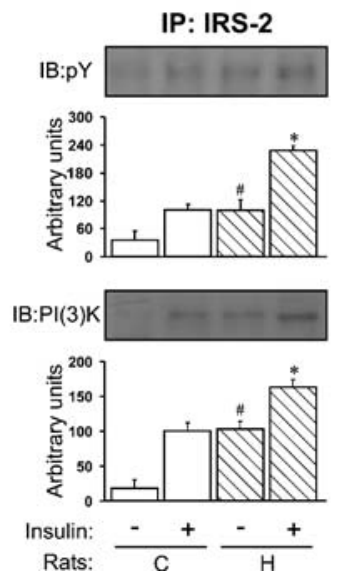

IP: IR

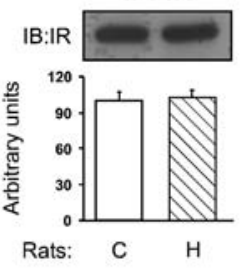

d
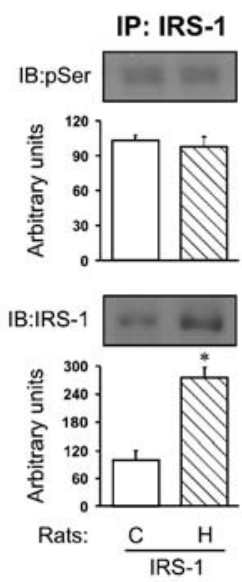

e
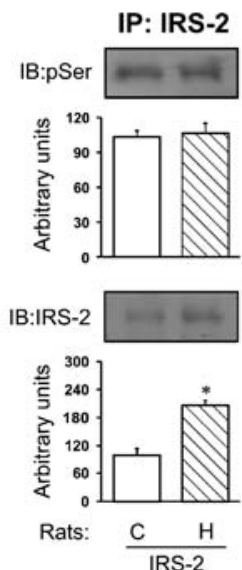

IP: IR

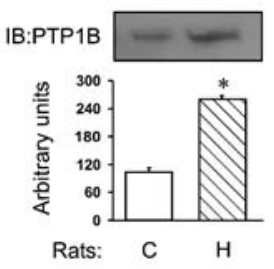

f

IRS-1

Phosphate (Tyr) protein
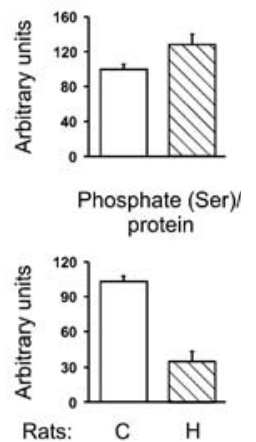

g

IRS-2

Phosphate (Tyr) protein

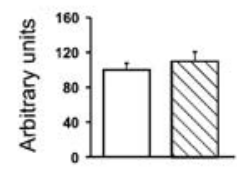

Phosphate (Ser) protein

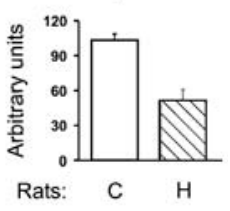

a

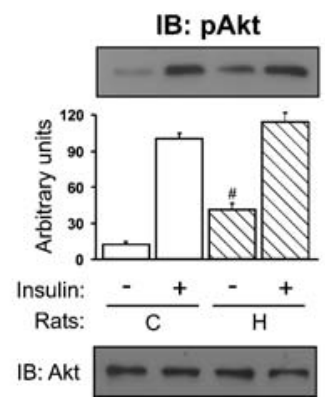

Fig. 6 Insulin signalling in the white adipose tissue of controls $(C)$ and hyperinsulinaemic $(H)$ rats. White adipose tissue extracts from rats injected with saline $(-)$ or insulin $(+)$ were prepared as described (see Materials and methods). Whole-tissue extracts were immuno- $\mathrm{b}$

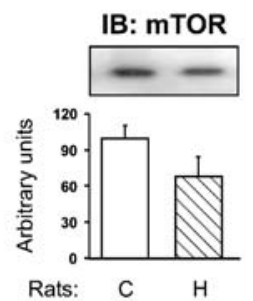

C

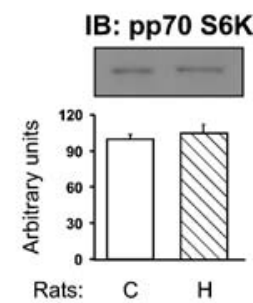

blotted $(I B)$ with anti-phospho Akt (a), anti-mTOR (b), or antiphospho-p70 S6K antibodies (c). The results of scanning densitometry $(n=8)$ are expressed as arbitrary units. Columns and bars represent the mean \pm SEM. ${ }^{*} p<0.05$, control vs hyperinsulinaemic 
IRS-1 and IRS-2 in white adipose tissue from control and hyperinsulinaemic rats was quantitated by immunoprecipitation and immunoblotting with anti-IRS-1 or anti-IRS-2 antibodies and higher expression levels of IRS-1 and IRS-2 proteins were observed (IRS-1: C: $100 \pm 4$ vs H: $274 \pm 13 \%$, $p<0.05$; IRS-2: C: $100 \pm 17$ vs H: $207 \pm 9 \%, p<0.05$; $n=8$;
Fig. 5d, e, lower panels). With respect to phosphorylation, when the data were corrected for the change in the number of IRS-1 molecules, the results showed a slight decrease in the apparent stoichiometry of IRS-1 tyrosine phosphorylation. However, a more than twofold decrease in IRS-1 serine phosphorylation was observed in the hyperinsulin-
Fig. 7 Effect of rapamycin on the insulin-induced serine phosphorylation of IRS-1/, mTOR levels and serine phosphorylation of p70 S6K in control $(C)$ and hyperinsulinaemic rats $(H)$ in liver $(\mathbf{a}-\mathbf{c})$, muscle $(\mathbf{d}-\mathbf{f})$ and white adipose tissue $(\mathbf{g}-\mathbf{i})$. Tissue extracts were immunoprecipitated $(I P)$ with anti-IRS-1 or anti-IRS-2 antibody and immunoblotted $(I B)$ with anti-pSer antibody or anti-IRS-1 and antiIRS-2. Tissue extracts were also immunoblotted with anti-mTOR or anti-phospho-p70 S6K antibodies. The results of scanning densitometry $(n=5)$ are expressed as arbitrary units. Columns and bars represent the mean \pm SEM. ${ }^{*} p<0.05$, control vs hyperinsulinaemic a

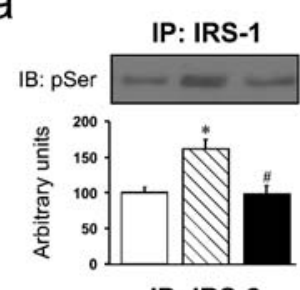

IP: IRS-2

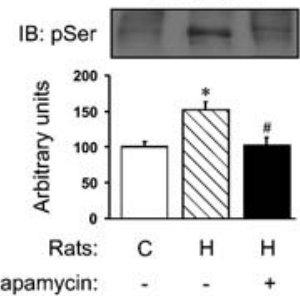

d

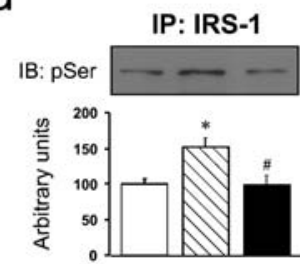

IP: IRS-2

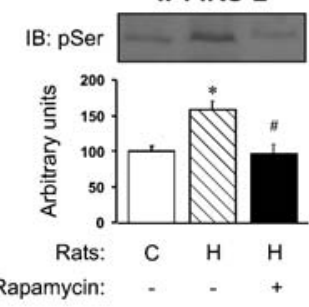

g

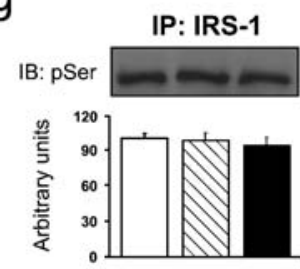

IP: IRS-2

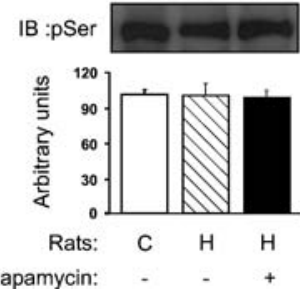

b
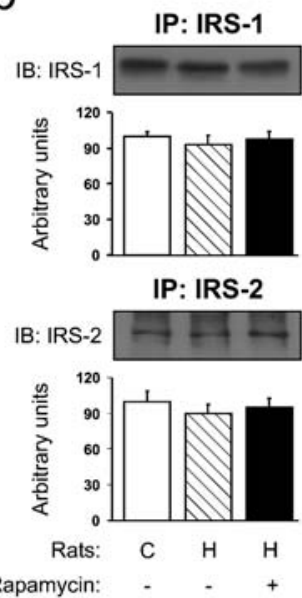

e

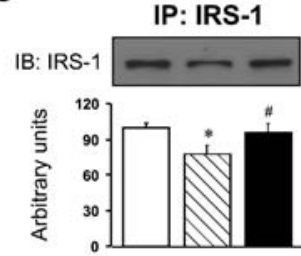

IP: IRS-2

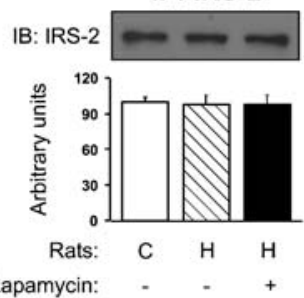

h

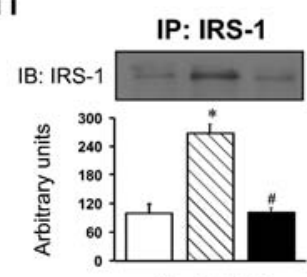

IP: IRS-2

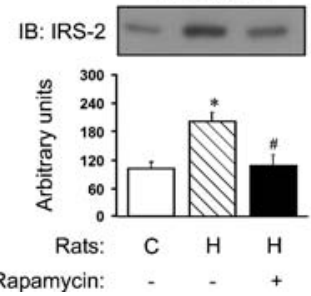

C

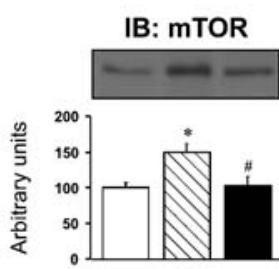

IB: pp70 S6K

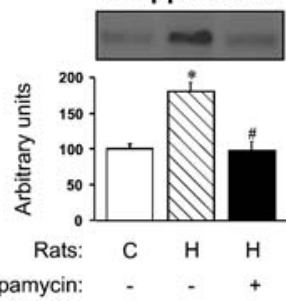

f

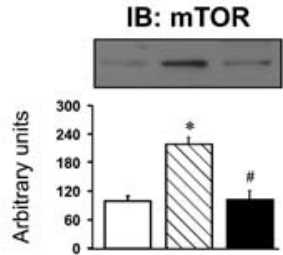

IB: pp70 S6K

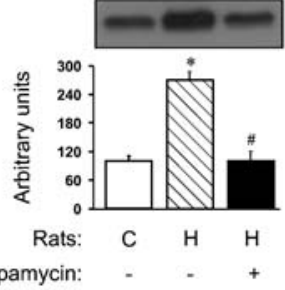

i

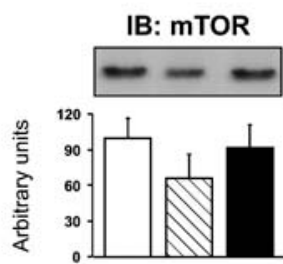

IB: pp70 S6K

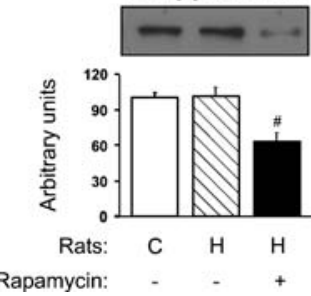


aemic rats (Fig. 5f). Similarly to the IRS-1 stoichiometry, the stoichiometry of IRS-2 tyrosine phosphorylation showed a modest decrease, and a more than twofold decrease in IRS-2 serine phosphorylation was seen in the hyperinsulinaemic rats (Fig. 5g).

We analysed insulin-induced Akt serine phosphorylation in whole-tissue extract using an anti-phospho Akt antibody. After stimulation with insulin, a band was observed indicating that Akt is phosphorylated in control and hyperinsulinaemic rats. Based on immunoreactivity, the basal phosphorylation level of Akt was higher in adipose tissue of hyperinsulinaemic rats than in control rats. However we did not observe differences in insulin-induced Akt serine phosphorylation (basal: C: $12 \pm 4$ vs $\mathrm{H}: 41 \pm 7 \%, p<0.05$; insulin-induced: C: $100 \pm 11$ vs H: $102 \pm 13 \%, p<0.05 ; n=8$; Fig. 6a). There was no difference in Akt protein levels (Fig. 6a, lower panel).

There was no differences in the basal mTOR protein expression $(\mathrm{C}=100 \pm 11$ vs $\mathrm{H}=69 \pm 17 \%, p=0.15, n=8$, Fig. $6 \mathrm{~b})$ and in the basal serine phosphorylation of p70 S6K $(\mathrm{C}=$ $100 \pm 8$ vs $\mathrm{H}=105 \pm 10 \%, p<0.05$; $n=8$, Fig. $6 \mathrm{c}$ ).

Rapamycin partially prevents changes in insulin resistance and IRS-1 and IRS-2 serine phosphorylation Whole-body insulin-mediated glucose disposal during the euglycaemic insulin clamp was significantly lower in rats treated with insulin for 5 days than in controls. Hyperinsulinaemic rats treated with rapamycin reversed hyperinsulinaemia-induced insulin resistance $(\mathrm{C}: 19 \pm 2 ; \mathrm{H}: 11 \pm 1 ; \mathrm{H}+$ rapamycin: $17 \pm 1$; $\mathrm{C}$ vs $\mathrm{H}, p<0.05$; $\mathrm{H}$ vs $\mathrm{H}+$ rapamycin, $p<0.05$ ). Hyperinsulinaemia induced a considerable increase in IRS- 1 and IRS-2 serine phosphorylation in the liver of rats. Treatment with rapamycin prevented hyperinsulinaemia-induced serine phosphorylation of IRS-1 and IRS-2 (Fig. 7a, b). To confirm the biological efficacy of mTOR blockage with rapamycin we determined the phosphorylation of p70 S6K in rats treated with rapamycin. Treatment with rapamycin prevented hyperinsulinaemia-induced reduction of mTOR levels and phosphorylation of p70 S6K (Fig. 7c). Similar results were observed in the muscle of the hyperinsulinaemic rats treated with rapamycin and, in addition, this drug also normalised the reduced IRS-1 protein expression induced by hyperinsulinaemia (Fig. $7 \mathrm{~d}-\mathrm{f}$ ).

Hyperinsulinaemia induced a marked increase in IRS-1 and IRS-2 protein levels in white adipose tissue of rats. Treatment with rapamycin prevented the hyperinsulinaemia-induced increase in IRS-1 and IRS-2 protein levels (Fig. $7 \mathrm{~g}, \mathrm{~h}$ ). To confirm the biological efficacy of mTOR blockage with rapamycin, we determined the phosphorylation of p70 S6K in rats treated with rapamycin. Treatment with rapamycin did not change mTOR levels, but induced a reduction in p70 S6K phosphorylation (Fig. 7i).

\section{Discussion}

We showed that chronic hyperinsulinaemic rats have insulin resistance accompanied by impairment of the insulininduced IR/IRSs/PI(3)K/Akt pathway in liver and muscle, which parallels increases in IRS1/2 serine phosphorylation, IR/PTP1B association and mTOR activity. In contrast, in white adipose tissue, there was an increase in IRS-1/2 protein levels, tyrosine phosphorylation and IRSs/ $\mathrm{PI}(3) \mathrm{K}$ association, leading to an increase in basal Akt serine phosphorylation, without changes in IRS-1/2 serine phosphorylation and mTOR activity. In addition, we demonstrated that inhibition of the mTOR pathway with rapamycin can prevent insulin resistance caused by chronic hyperinsulinaemia in liver and muscle. Taken together, our data demonstrate a defective and tissue-selective insulin action, which could contribute to the insulin resistance observed in hyperinsulinaemic states.

Our results show that, in liver, there was a decrease in the IR/IRS-2/Akt pathway, and surprisingly we did not observe differences in IRS-1 protein expression, tyrosine phosphorylation and association with $\mathrm{PI}(3) \mathrm{K}$. Conversely, in muscle, we observed a decrease in the IR/IRS-1/Akt pathway, accompanied by a reduction in IRS- 1 protein level, and we did not observe differences in IRS-2 tyrosine phosphorylation. In accordance with our data, several lines of evidence suggest important tissue-specific roles for IRS-1 and IRS-2 in mediating the effect of insulin on carbohydrate metabolism in vivo. Kido and co-workers [24] demonstrated that mice with a combined heterozygous disruption of the insulin receptor and IRS-1 $\left(I R^{+/} / I R S-1^{+-}\right)$ develop severe muscle insulin resistance and a reduction in insulin-stimulated PI(3)K activation. In contrast, the muscle defects in $I R^{+/} / I R S-2^{+/-}$mice in these parameters are less significant. Moreover, insulin resistance in the $I R S-1^{-1}$ mice could be ascribed mainly to decreased insulin-stimulated peripheral glucose metabolism. In contrast, IRS $-2^{-/}$ mice displayed multiple defects in insulin-mediated carbohydrate metabolism as reflected by decreased peripheral glucose utilisation, decreased suppression of endogenous glucose production and decreased hepatic glycogen synthesis $[25,26]$. In accordance with the important role of Akt in glycogen synthesis [27], we observed that the hepatic and muscular glycogen content was significantly lower in the chronic insulin-treated rats than in the controls. The results observed in this study with changes in the IR/IRS-2/PI(3) $\mathrm{K} /$ Akt pathway in liver and the IR/IRS-1/PI(3)K/Akt pathway in muscle suggest that the insulin receptor substrate that drives insulin resistance in liver is IRS-2, and that the receptor substrate driving insulin resistance in muscle is IRS-1.

Our data show that hyperinsulinaemia modulates insulin signalling in liver and muscle, probably by more than one mechanism. In hyperinsulinaemic animals, there is an increase in PTP1B association with IR in liver and muscle. Since IR/PTP1B interaction may dephosphorylate the insulin receptor and impair insulin signalling, the reduced insulin-induced receptor phosphorylation observed in hyperinsulinaemic rats may in part be a consequence of this increased association. These alterations in the insulin receptor may play a role in the reduction in insulin-induced IRS-1/2 tyrosine phosphorylation and association with PI3-kinase and in Akt serine phosphorylation in the liver and muscle of hyperinsulinaemic animals. 
Increased Ser/Thr phosphorylation of IRSs has been proposed as a major cause of insulin resistance induced by a variety of agents such as TNF- $\alpha$, okadaic acid, plateletderived growth factor, protein kinase $\mathrm{C}$ activators, and chronic hyperinsulinaemia. Furthermore, insulin resistance induced by chronic hyperinsulinaemia has been shown to involve the activation of a rapamycin-sensitive pathway $[14,28-31]$. Therefore, the present investigation together with previous studies shows that the increased activity of $\mathrm{mTOR} / \mathrm{p} 70 \mathrm{~S} 6 \mathrm{~K}$ pathway phosphorylation and the resulting increase in IRS-1 and IRS-2 on Ser/Thr residues modulate insulin resistance in hyperinsulinaemic rats. Although it is unknown whether mTOR and/or p70 S6K directly phosphorylate IRS-1, mTOR kinase activity has been shown to be directed toward sites containing a (Ser/ Thr)-Pro motif [32] such as that encountered in the IRS-1 structure [33]. Interestingly, the IR/IRS-1/PI(3)K/Akt pathway is down-regulated in the liver and muscle of hyperinsulinaemic rats and $\mathrm{p} 70 \mathrm{~S} 6 \mathrm{~K}$, which is downstream to Akt/mTOR and shows increased activity. Previous data showed similar results in the muscle of a transgenic mouse with a severe defect in insulin receptor kinase [34], and it has also been reported that p70 S6K was substantially activated by insulin in 32D cells transfected with IRS-1 alone, whereas significant insulin-mediated PI(3)K (or MAP kinase) was not evident without overexpression of both IRS-1 and insulin receptors [35]. Together with ours, these results suggest that stimulation of p70 S6K is selectively preserved in the liver and muscle of hyperinsulinaemic rats, indicating signal amplification in the pathways leading to these effects. In addition, our results also showed an increase in mTOR protein expression, probably contributing to its increased activity, as demonstrated by p70 S6K phosphorylation.

The inter-dependence of multiple tissues in determining overall metabolic control leads us to question whether the primary abnormality in hyperinsulinaemia is restricted to a specific target organ of insulin action or represents a generalised failure to respond to insulin [24]. Therefore, we investigated the role of white adipose tissue in insulin resistance in hyperinsulinaemic rats. Our results show that insulin-stimulated IR tyrosine phosphorylation is similar in chronic hyperinsulinaemic rats and controls and is accompanied by an increase in IRS-1/2, protein levels, tyrosine phosphorylation and $\mathrm{PI}(3) \mathrm{K}$ association, resulting in increased serine phosphorylation of Akt basal levels. Consistent with these results, we did not observe differences in IRS-1/2 serine phosphorylation and mTOR/p70S6K activity between controls and hyperinsulinaemic rats. However, IR/PTP1B association did increase in white adipose tissue of chronic hyperinsulinaemic rats. Data from different sources suggest that the effectiveness of PTP1B in reducing IR and IRS-1 tyrosyl phosphorylation differs in different cell types $[11,36]$. In adipose tissue, under physiological conditions, PTP1B may not play an important role in dephosphorylation of the insulin receptor and IRS-1, which is in contrast to muscle and liver. Another study [36] demonstrated that, even in the presence of massive expression of PTP1B in adipocytes, there is only a modest decrease in IR and IRS-1 tyrosyl phosphorylation, without changes in insulin-induced Akt activity. These findings suggest that PTP1B alone may not be a physiologically important mediator of normal insulin signalling in fat cells, although it appears to be rate-limiting for insulin action in other insulin target tissues such as liver and muscle [11].

Since hyperinsulinaemia and increased glucose transport in adipocytes have been implicated as important stimuli for enhanced fat synthesis and the development of obesity, our results provide a possible molecular mechanism for the pathogenesis of insulin resistance in liver and muscle and hypersensitivity in the adipose tissue of hyperinsulinaemic animals.

Thus, insulin resistance in the muscle and liver contrasts greatly with the ability of insulin to stimulate the IRSs/PI (3)K pathway in the adipose tissue of hyperinsulinaemic rats. This effect of hyperinsulinaemia dissociating the insulin action in adipose tissue and muscle was also observed in other studies $[10,37]$ in animals with increased adiposity. Our data on insulin signalling is in accordance with previous data [38-41] showing that hyperinsulinaemia, imposed on normal rats, increases glucose uptake, lipogenesis and fat accumulation in white adipose tissue, whilst producing reduced glucose utilisation.

Insulin-induced serine phosphorylation and degradation of IRS-1 and IRS-2 in liver and muscle seem to play a major role in down-regulation of insulin signalling, since inhibition of mTOR with rapamycin recovers glucose disposal after chronic hyperinsulinaemia. Rapamycin acts by binding mTOR as a complex with FKBP12, thus compromising the catalytic activity of mTOR (31/32). Therefore, mTOR itself or a serine threonine kinase regulated by mTOR may be responsible for the insulin-induced serine phosphorylation of IRS-1 and IRS-2 in liver and muscle. In contrast, rapamycin prevents the increase in IRS-1/2 expression caused by chronic hyperinsulinaemia in white adipose tissue.

In summary, our data show that chronic hyperinsulinaemia itself, imposed on normal rats, appears to have a dual effect, stimulating insulin signalling in white adipose tissue, but decreasing it in liver and muscle. In addition, we have demonstrated that inhibition of the mTOR pathway with rapamycin can prevent insulin resistance caused by chronic hyperinsulinaemia in liver and muscle. The underlying mechanism of these differential effects may be related to the ability of hyperinsulinaemia to increase mTOR/p70 S6K pathway activity and IRS-1/2 serine phosphorylation in a tissue-specific fashion. These findings support the hypothesis that defective and tissue-selective insulin action contributes to the insulin resistance observed in hyperinsulinaemic states. 


\section{References}

1. Ferrannini E, Haffner SM, Mitchell BD, Stern MP (1991) Hyperinsulinaemia: the key feature of a cardiovascular and metabolic syndrome [see comment]. Diabetologia 34:416-422

2. DeFronzo RA (1992) Pathogenesis of type 2 (non-insulin dependent) diabetes mellitus: a balanced overview. Diabetologia 35:389-397

3. Cheatham B, Kahn CR (1995) Insulin action and the insulin signaling network. Endocr Rev 16:117-142

4. Folli F, Saad MJ, Backer JM, Kahn CR (1992) Insulin stimulation of phosphatidylinositol 3-kinase activity and association with insulin receptor substrate 1 in liver and muscle of the intact rat. J Biol Chem 267:22171-22177

5. Saad MJ, Folli F, Kahn JA, Kahn CR (1993) Modulation of insulin receptor, insulin receptor substrate-1, and phosphatidylinositol 3-kinase in liver and muscle of dexamethasone-treated rats. J Clin Invest 92:2065-2072

6. Downward J (1998) Mechanisms and consequences of activation of protein kinase B/Akt. Curr Opin Cell Biol 10:262-267

7. Chen R, Kim O, Yang J et al (2001) Regulation of Akt/PKB activation by tyrosine phosphorylation. J Biol Chem 276:3185831862

8. Ventre J, Doebber T, Wu M et al (1997) Targeted disruption of the tumor necrosis factor-alpha gene: metabolic consequences in obese and nonobese mice. Diabetes 46:1526-1531

9. Greene MW, Sakaue H, Wang L, Alessi DR, Roth RA (2003) Modulation of insulin-stimulated degradation of human insulin receptor substrate- 1 by Serine 312 phosphorylation. J Biol Chem 278:8199-8211

10. Hirata AE, Alvarez-Rojas F, Carvalheira JB, Carvalho CR, Dolnikoff MS, Abdalla Saad MJ (2003) Modulation of IR/ PTP1B interaction and downstream signaling in insulin sensitive tissues of MSG-rats. Life Sci 73:1369-1381

11. Elchebly M, Payette P, Michaliszyn E et al (1999) Increased insulin sensitivity and obesity resistance in mice lacking the protein tyrosine phosphatase-1B gene [comment]. Science 283: $1544-1548$

12. Sekulic A, Hudson CC, Homme JL et al (2000) A direct linkage between the phosphoinositide 3-kinase-AKT signaling pathway and the mammalian target of rapamycin in mitogenstimulated and transformed cells. Cancer Res 60:3504-3513

13. Li PM, Goldstein BJ (1996) Differential regulation of insulinstimulated tyrosine phosphorylation of IRS-1 and SHC by Wortmannin in intact cells. Biochem Biophys Res Commun 223:80-84

14. Haruta T, Uno T, Kawahara J et al (2000) A rapamycinsensitive pathway down-regulates insulin signaling via phosphorylation and proteasomal degradation of insulin receptor substrate-1. Mol Endocrinol 14:783-794

15. Ozes ON, Akca H, Mayo LD et al (2001) A phosphatidylinositol 3-kinase/Akt/mTOR pathway mediates and PTEN antagonizes tumor necrosis factor inhibition of insulin signaling through insulin receptor substrate-1. Proc Natl Acad Sci U S A 98:4640-4645

16. Koopmans SJ, Ohman L, Haywood JR, Mandarino LJ, DeFronzo RA (1997) Seven days of euglycemic hyperinsulinemia induces insulin resistance for glucose metabolism but not hypertension, elevated catecholamine levels, or increased sodium retention in conscious normal rats. Diabetes 46:1572-1578

17. DeFronzo RA, Tobin JD, Andres R (1979) Glucose clamp technique: a method for quantifying insulin secretion and resistance. Am J Physiol 237:E214-E223

18. Laemmli UK (1970) Cleavage of structural proteins during the assembly of the head of bacteriophage T4. Nature 227:680-685

19. Towbin H, Staehelin T, Gordon J (1979) Electrophoretic transfer of proteins from polyacrylamide gels to nitrocellulose sheets: procedure and some applications. Proc Natl Acad Sci U S A $76: 4350-4354$
20. Bradford MM (1976) A rapid and sensitive method for the quantitation of microgram quantities of protein utilizing the principle of protein-dye binding. Anal Biochem 72:248-254

21. Trinder P (1969) Determination of blood glucose using an oxidase-peroxidase system with a non-carcinogenic chromogen. J Clin Pathol 22:158-161

22. Scott AM, Atwater I, Rojas E (1981) A method for the simultaneous measurement of insulin release and B cell membrane potential in single mouse islets of Langerhans. Diabetologia 21:470-475

23. Lo S, Russell JC, Taylor AW (1970) Determination of glycogen in small tissue samples. J Appl Physiol 28:234-236

24. Kido Y, Burks DJ, Withers D et al (2000) Tissue-specific insulin resistance in mice with mutations in the insulin receptor, IRS-1, and IRS-2. J Clin Invest 105:199-205

25. Previs SF, Withers DJ, Ren JM, White MF, Shulman GI (2000) Contrasting effects of IRS-1 versus IRS-2 gene disruption on carbohydrate and lipid metabolism in vivo. J Biol Chem 275: 38990-38994

26. Withers DJ, Gutierrez JS, Towery H et al (1998) Disruption of IRS-2 causes type 2 diabetes in mice. Nature 391:900-904

27. Kitamura T, Ogawa W, Sakaue H et al (1998) Requirement for activation of the serine-threonine kinase Akt (protein kinase B) in insulin stimulation of protein synthesis but not of glucose transport. Mol Cell Biol 18:3708-3717

28. Li J, DeFea K, Roth RA (1999) Modulation of insulin receptor substrate-1 tyrosine phosphorylation by an Akt/phosphatidylinositol 3-kinase pathway. J Biol Chem 274:9351-9356

29. Tanti JF, Gremeaux T, van Obberghen E, Le Marchand-Brustel Y (1994) Serine/threonine phosphorylation of insulin receptor substrate 1 modulates insulin receptor signaling. J Biol Chem 269:6051-6057

30. Hotamisligil GS, Peraldi P, Budavari A, Ellis R, White MF, Spiegelman BM (1996) IRS-1-mediated inhibition of insulin receptor tyrosine kinase activity in TNF-alpha- and obesityinduced insulin resistance. Science 271:665-668

31. De Fea K, Roth RA (1997) Protein kinase C modulation of insulin receptor substrate-1 tyrosine phosphorylation requires serine 612. Biochemistry 36:12939-12947

32. Brunn GJ, Fadden P, Haystead TA, Lawrence JC Jr (1997) The mammalian target of rapamycin phosphorylates sites having a (Ser/Thr)-Pro motif and is activated by antibodies to a region near its $\mathrm{COOH}$ terminus. J Biol Chem 272:32547-32550

33. Sun XJ, Rothenberg P, Kahn CR et al (1991) Structure of the insulin receptor substrate IRS-1 defines a unique signal transduction protein. Nature 352:73-77

34. Chang PY, Le Marchand-Brustel Y, Cheatham LA, Moller DE (1995) Insulin stimulation of mitogen-activated protein kinase, p90rsk, and p70 S6 kinase in skeletal muscle of normal and insulin-resistant mice. Implications for the regulation of glycogen synthase. J Biol Chem 270:29928-29935

35. Myers MG Jr, Grammer TC, Wang LM et al (1994) Insulin receptor substrate-1 mediates phosphatidylinositol 3'-kinase and p70S6k signaling during insulin, insulin-like growth factor-1, and interleukin-4 stimulation. J Biol Chem 269:2878328789

36. Venable CL, Frevert EU, Kim YB et al (2000) Overexpression of protein-tyrosine phosphatase-1B in adipocytes inhibits insulin-stimulated phosphoinositide 3-kinase activity without altering glucose transport or Akt/protein kinase B activation. J Biol Chem 275:18318-18326

37. Thirone AC, Carvalheira JB, Hirata AE, Velloso LA, Saad MJ (2004) Regulation of Cbl-associated protein/Cbl pathway in muscle and adipose tissues of two animal models of insulin resistance. Endocrinology 145:281-293 
38. Krief S, Bazin R, Dupuy F, Lavau M (1988) Increased in vivo glucose utilization in 30-day-old obese Zucker rat: role of white adipose tissue. Am J Physiol 254:E342-E348

39. Cusin I, Terrettaz J, Rohner-Jeanrenaud F, Jeanrenaud B (1990) Metabolic consequences of hyperinsulinaemia imposed on normal rats on glucose handling by white adipose tissue, muscles and liver. Biochem J 267:99-103
40. Cusin I, Terrettaz J, Rohner-Jeanrenaud F, Zarjevski N, Assimacopoulos-Jeannet F, Jeanrenaud B (1990) Hyperinsulinemia increases the amount of GLUT4 mRNA in white adipose tissue and decreases that of muscles: a clue for increased fat depot and insulin resistance. Endocrinology 127:3246-3248

41. Jeanrenaud B, Halimi S, van de Werve G (1985) Neuroendocrine disorders seen as triggers of the triad: obesity-insulin resistance-abnormal glucose tolerance. Diabetes Metab Rev 1: 261-291 